\title{
Sensor Networks or Smart Artifacts? An Exploration of Organizational Issues of An Industrial Health and Safety Monitoring System
}

\author{
Gerd Kortuem $^{1}$, David Alford ${ }^{2}$, Linden Ball ${ }^{2}$, Jerry Busby ${ }^{3}$, Nigel Davies ${ }^{1}$, Christos \\ Efstratiou $^{1}$, Joe Finney ${ }^{1}$, Marian Iszatt White ${ }^{3}$, Katharina Kinder ${ }^{3}$ \\ ${ }^{1}$ Computing Department, InfoLab21, Lancaster University, Lancaster, LA1 4WA, UK \\ \{kortuem,nigel,efstrati\}@comp.lancs.ac.uk, finneyj@v6testbed.net \\ ${ }^{2}$ Department of Psychology, Lancaster University, Lancaster, LA1 4YF, UK \\ \{d.alford,1.ball\}@lancaster.ac.uk \\ ${ }^{3}$ Management School, Lancaster University, Lancaster, LA1 4YX, UK \\ \{j.s.busby,m.iszattwhite,k.kinder\}@lancaster.ac.uk
}

\begin{abstract}
Industrial health and safety is an important yet largely unexplored application area of ubiquitous computing. In this paper we investigate the relationship between technology and organization in the context of a concrete industrial health and safety system. The system is designed to reduce the number of incidents of "vibration white finger" (VWF) at construction sites and uses wireless sensor nodes for monitoring workers' exposure to vibrations and testing of compliance with legal health and safety regulations. In particular we investigate the impact of this ubiquitous technology on the relationship between management and operatives, the formulation of health and safety rules and the risk perception and risk behavior of operatives. In addition, we contrast sensornetwork inspired and smart artifact inspired compliance systems, and make the case that these technology models have a strong influence on the linkage between technology and organization.
\end{abstract}

Keywords: ubiquitous computing, sensor network, smart artifact, workplace support, occupational health and safety, safety culture, risk management, compliance architecture, organizational fit, privacy.

\section{Introduction}

Industrial workplaces such as construction sites, factories and plants pose enormous risks for workers and operatives. The International Labor Organization has estimated that some two million people die every year from work-related accidents and diseases worldwide [1]. An estimated 160 million people suffer from work-related diseases, and there are an estimated 270 million fatal and non-fatal work-related accidents per year. In economic terms, this means that $4 \%$ of the world's annual GDP is lost as a consequence of occupational diseases and accidents. Lowering occupational risks has long been the focus of legal authorities and industrial firms. It is an interesting and important question to ask if and how ubiquitous computing can play a role in making industrial workplaces safer. 
Ubiquitous tracking and monitoring technologies are now routinely used in industrial environments [2,3], but very rarely with the goal to improve occupational health and safety. Research in ubiquitous computing has shown promise in healthrelated domains such as hospitals [4], elder care [5] and emergency rescue [6], yet applications in industrial settings are few. Over the last $1 \frac{1 / 2}{2}$ year, we have explored ubiquitous computing technologies for industrial workplaces, with a special focus on health and safety. In particular, we developed a sensor-based system designed to reduce the number of incidents of "vibration white finger" (VWF) at construction sites [7]. The system monitors workers' exposure to vibrations when using heavyduty equipment such as pneumatic drills, tests compliance with legal health and safety regulations in real-time and creates detailed data records of worker's vibration exposure.

An industrial organization is a complex socio-technical system that is characterized by the formal and informal practices, rules and habits that influence interactions between people and groups in the organization. Designing technology, such as our vibration monitoring system, to fit established work practices and to function properly within an existing organization is a difficult task. Novel technology may disturb the balance between the various players and result in unintended and unforeseen consequences. To minimize the risk of failure it is essential that we assess a system's potential impact on work practices and identify an appropriate linkage between technology and organization as early as possible in the design process. This problem has been widely researched in the information systems community [8,9], but is just beginning to receive attention with regard to ubiquitous computing [10].

In the context of the previously mentioned vibration monitoring case study this paper makes two specific contributions: First, we identify work-organizational issues that are relevant for ubiquitous health and safety systems. According to Doherty and King [11] organizational issues are issues that need to be treated during the systems development process to ensure that the individual human, wider social, and economic impacts of the resultant technical system are likely to be desirable. In particular we investigate the representation of health and safety rules, the relationship between operatives and management, and operatives' risk perception and risk behavior. We argue that these issues need to be understood to enable successful introduction of ubiquitous health and safety technology in industrial environments.

Second, we define two fundamental architectural alternatives for a ubiquitous health and safety system and illuminate the architecture's influence on organizational issues. The first architecture is based on the concept of sensor networks and the second is built around the notion of smart everyday objects. Both models represent archetypes that have a great influence in ubiquitous computing research. We discuss how these models differ with respect to centralization and locality and how they may impact in different ways on safety behavior, accountability and formulation of health and safety rules. In essence we argue that system architecture is not neutral, but plays a crucial part in shaping work-organizational factors and thus influences the overall success or failure of a ubiquitous computing system in an organization.

The research reported in this paper is part of the interdisciplinary NEMO project. In previous publications we identified research challenges of ubiquitous health and safety system [12], reported our experiences in building and field-testing technology prototypes [7], explored safety culture and risk management at participating industrial 
firms [13,14], and studied human reasoning about health and safety rules [15]. In contrast, this paper focuses on the interplay of technology and organization.

In the remainder of the paper we start our discussion with a description of the "vibration white finger" case study (Section 2). This is followed by a discussion of methodological considerations when developing technologies to fit organizations (Section 3). Next we explore the sensor network and smart artifact models as two opposing alternatives for designing a ubiquitous health and safety system (Section 4). This lays the basis for an in-depths discussion of organizational issues and especially the linkage between system architecture and organization (Section 5).

\section{Case Study: Controlling Hand-Arm Vibrations}

Most industrial organizations do their utmost to reduce the risks associated with work activities and to provide a safe and healthy work environment. The reasons for this can be attributed to economic, legal and social pressures. As a matter of fact, health and safety compliance has today become a strategic objective for many large companies [16]. To prove compliance, organizations need to provide evidence that appropriate controls are in place - and that they work. While this can be done in several ways, it commonly involves data collection and record keeping, a process that is time consuming and costly. As a result of the mounting legislative pressure and the increasing need to prove compliance, companies have started to look for innovative ways to ensure workplace safety and are increasingly using enterprise-wide health and safety management systems. We believe that ubiquitous computing technology and embedded wireless systems offer a great potential for improving health and safety processes. Similarly, industrial safety exposes important new research challenges for ubiquitous computing [12].

As part of the NEMO project we have teamed up with major industrial firms to identify health and safety scenarios and to study technology in-situ through field trials and workplace studies. One of the first scenarios to come out of this project relates to the potential damage caused by vibrations when operating hand machinery such as hydraulic drills and breakers. Long-term exposure to hand arm vibration (HAV) can lead to serious health conditions known as "vibration white finger" (VWF) and in extreme cases to life-long disability. VWF is triggered by prolonged use of vibrating machinery, and causes the fingers to become numb and to begin turning white. In a progressive stadium the disease is irreversible; the person suffers increasingly frequent painful attacks at any time and may even lose their fingers. In order to understand how companies deal with this problem we investigated legal requirements and observed work practices at a major road construction and service company (referred to in this paper as Safe-company). The following provides a summary of our key observations.

\subsection{Vibration-Related Health and Safety Regulations}

Extensive health and safety regulations exist to limit workers' exposure to HAV. For example, in 2005 the UK Parliament introduced the Control of Vibration at Work Regulations [17]. The guidelines place a responsibility on employers to assess every 
employee's risk and to consider the specific individual working conditions of each employee. The damage caused by exposure to vibration is a combination of both the frequency of the vibrating tool and the duration of the exposure [18]. Using a tool that vibrates slightly for a long time can be as damaging as using a heavily vibrating tool for a short time. Thus regulations introduce action and limit values for hand-arm vibration [19]:

- Exposure action value of $2.5 \mathrm{~m} / \mathrm{s}^{2} \mathrm{~A}(8)$ at which level employers should introduce technical and organizational measures to reduce exposure.

- Exposure limit value of $5.0 \mathrm{~m} / \mathrm{s}^{2} \mathrm{~A}(8)$ which should not be exceeded in all circumstances.

These values are defined in terms of the average daily exposure dose $\mathrm{A}(8)$ which is specific to each equipment and provided by manufacturers. In practice an operative's vibration exposure can be estimated from three parameters: the equipment type, the duration of use and the surface hardness (soft, medium, hard).

\subsection{Safety-related Work Practices}

\subsubsection{Methodology}

In order to understand how organizations address vibration-induced health concerns we conducted an ethnographic study of work practices at Safe-company (see also $[13,14])$. The organization itself saw its emphasis on safety as a unique selling point in tendering for new business, and its ability to publicize its involvement with a major research project in this area as contributing to its safety conscious image. The fieldwork for the study consisted of a number of semi-structured interviews with operatives and supervisory and management staff, aimed at drawing out 'sensitizing concepts' to inform the later stages of the fieldwork, followed by the extended observation of operatives, together with the collection of documents and other artifacts, with the aim of developing a rich understanding of the setting, including working practices, safety and audit culture perceptions, and concerns in relation to technology. A coding template [20] was then developed to structure the analysis of interview/fieldwork data, including the theorizing of links between various levels of coding, and the location of the template in the existing literature. The findings from this process were used to inform the technology design and implementation process on an ongoing basis. In total, the study involved more than 40 people from Safecompany (including high-level management, supervisors and operatives), spanning over 18 months and 6 different work sites.

As part of the interview phase, the interviewees were asked to grant access to others within the specific contracts on which they worked, in order to construct the subsequent program of fieldwork. The fieldwork observations included participation in safety training, observation of a wide range of on-site activities, attendance at safety-related meetings (for example, at a number of multi-level, multi-disciplinary Safety Action Group meetings), and informal discussions with site operatives. The latter took place both in one-to-one situations (for example, whilst observing them at their work or driving with them in their vehicles) and in small groups, usually when operatives were eating their lunch in the site mess rooms. A range of organizational and sector-related documents were also obtained. 


\subsubsection{Work Practices}

Our investigations at Safe-company focused on smallish maintenance work, rather than new construction. Such work is usually carried out by two-men crews that drive to the location of defects to carry out repair work prescribed in work orders. The work requires the use of heavy-duty pneumatic drills for breaking open tarmac, saws for cutting square holes in the tarmac surrounding potholes, and wacker plates for compacting new tarmac. Such equipment can only be operated by one worker at a time, but workers frequently switch, passing the tool between them. With regard to pneumatic drills our observations revealed that drilling tends to happen in bouts of 1-5 minutes at a time, with 2-3 bouts per patch, but on occasion may take up to about half an hour. Operatives often interrupt work for brief moments to turn or place the drill. A crew may do 5-20 patches per day depending on the size of the patches and the distance they have to travel between them. For example, one crew did six patches of between $30 \mathrm{~cm}^{2}$ and one square meter, with quite a lot of driving around in between, while another one had a row of nine small patches to do within 100 yards of each other, each one about $30 \mathrm{~cm}^{2}$.

\subsubsection{Current Compliance Practice}

Workers are advised about safety procedures and the dangers of VWF in so-called toolbox talks. These are a weekly events that cover a variety of topics, most of them safety related. They often only last 10-15 minutes, are conducted in lunch breaks or out on site, and are repeated 2-3 times in the course of the day until everyone has attended a session. To minimize health damage, the company requires workers to wear ear protectors, safety glasses and gloves. Vibration exposure data is manually recorded by operatives on paper sheets, where exposure times and the type of tool used are noted (surface conditions are usually ignored and assumed to be 'hard'). Workers hand these sheets to their supervisors at the end of the day or week and the data in processed in the backend, often in a central database at the company headquarters. Supervisors will often (but not always) advise workers on the cumulative amount of exposure.

The system relies on workers diligently recording their exposure times and handing back records to supervisors on time. In practice we observed that this could be difficult since throughout a day a worker may use various vibrating tools at several work sites. Exposures were hand timed by operatives and entered on a paper record sheet. This record was often made retrospectively (for example, all exposures for the morning working hours were 'calculated' and entered on the sheet whilst sitting in the truck having lunch) and the process of hand timing was little more than guesswork. Thus the current practice raises serious concerns with respect to completeness, accuracy and consistency of captured data.

\subsubsection{Risk Perception}

The dangers posed by vibrations can be classified as 'invisible risks', i.e. risks with a loose or delayed linkage between the risk and its outcomes. Invisible risks, even if appropriately assessed and documented at an organizational level, are often underestimated or viewed as insignificant by operatives. Asking operatives about the risks of hand arm vibration (HAV) was regularly met with a variation of 'well, I've 
been doing this job for twenty years and I haven't had any problems with it'. Whilst everyone seemed to know someone who had suffered from vibration white finger, this was insufficient to make the risk appear 'real' in relation to their own conduct. Most accidents in the industry happen through trips, slips and falls, and the most prominent danger to the workers' lives is posed by road accidents involving cars driving by the work sites. In comparison to this, operatives seem to neglect or disregard a long-term risk such as vibration white finger as a less immediate danger. Managers and supervisors, in contrast, tended to be well aware of invisible risks and of the problems associated with conveying this risk to operatives.

We observed that the lack of recognition of vibration as a serious risk was exacerbated by the imprecise and low-key method of collecting exposure data. Operatives viewed the system as impractical in relation to actually getting the work done - i.e. timing and adding up a series of short bursts would be very disruptive to the work itself - and its low-key nature suggested to them that it was not important enough to attempt to do more accurately.

\subsection{Real-time Compliance Monitoring as an Opportunity for Ubiquitous Computing}

A wide variety of IT solutions for managing health and safety compliance exist, yet with respect to hand-arm vibrations our investigations have identified a distinctive lack of tailored solutions. The current practice can be improved using mobile data entry solutions based on handheld wireless computers. Yet, while mobile solutions reduce the need for paper forms, they still suffer from the fact that they rely on human information gathering and recording in the field.

Whereas audits are often seen as one-off events, compliance-related legislation and regulation increasingly contains requirements for ongoing and real-time monitoring of the level of compliance. This opens an opportunity for sensor-based ubiquitous systems to improve health and safety compliance. Technologies such as wireless sensor network and wearable sensors can be designed to extract salient information from the workplace, recognize work activities and interpret them (possibly in realtime) with regard to health and safety regulations. In particular we see three beneficial uses of ubiquitous technologies: 1) Improving the quality of recorded health and safety data. 2) Providing timely, personalized notices to workers and operatives about health and safety risks. 3) Improving the understanding of company-wide health and safety risks.

\section{Designing Technologies to Fit Organizations: Methodological Considerations}

To minimize project risks, organizational issues should be considered from the very beginning of the development process, starting with idea generation and market assessment. In reality, however, this is rarely the case. A study exploring to what extent organizational issues are proactively managed in design processes of ubiquitous computing technologies found that (a) wider organizational aspects are perceived to be less of less importance than user centered issues and those directly 
related to the effective functioning of the technologies, and that (b) even those organizational issues that are considered to be of importance do not actually influence the design process [10].

Designing technologies for industrial organizations requires an understanding of the roles, needs and expectations of a variety of stakeholders. In our case study we are concerned with legal authorities, insurance companies, management, supervisors and operatives. Not every stakeholder has the same influence on the design process and the resulting system might benefit one stakeholder (for example management) to the detriment of another (for example operatives). Such a situation can lead to conflicts that negatively impact the functioning of the overall organization and, in our case, could mean a worsening of the company's health and safety record.

There is a particular danger that development is driven by technology visions, rather than by a grounded understanding of the organization and its business environment. On the other hand, in order to innovate we cannot always wait until we have a full understanding of these issues. Many questions will only come to light once we had a chance to try things out in the real world. Thus, we are faced with a methodological problem: how can we design technology if we do not fully understand the organizational environment, and how can we assess a technology that has not yet fully materialized and that has not yet been deployed within the organization? This is a problem that is common to technology innovation but especially profound for ubiquitous computing technologies that have the potential to fundamentally alter established principles and practices. A similar problem is described in [21]. To solve this methodological problem we use an approach combining five elements:

- Development of technology-driven demonstrators

- Field trials of technology prototypes

- Observational work place studies

- Lab-based human studies

- Comparative studies of prior technology deployments

The observational studies are described above. We use lab-based studies to explore questions of human perception, understanding and interaction with technology (see [15] for some results). Studies of prior technology deployments are concerned with similar technologies deployed within other companies and different technologies deployed within the same organization. For example, we investigated Safe-company's use of GPS technology for tracking vehicles. This technology was introduced by the management a few years prior to our investigations and was often used as a reference point by operatives and management.

\section{Architectural Models for Ubiquitous Health and Safety Systems}

In this section we identify two fundamental alternative system models for a ubiquitous compliance system. The first is based on the concept of sensor networks and the second is built around the notion of smart everyday objects. Both models represent archetypes that are intuitively understood by ubiquitous computing researchers, even though their technical realization may be less well defined. Their importance lies in the fact that they lead to highly diverging compliance regimes. These models inspired the construction of a prototype vibration monitoring system 
that was tested during a 2-week long field trial at Safe-company ([7], see also Section 4.3). Section 5 then explores the divergent impact of these system models on organizational issues.

\subsection{The Sensor Network Approach}

The concept of wireless sensor-networks (and smart dust) originally arose in the context of military applications and since then has been extended to civilian applications. Wireless sensor networks are beginning to be used in the industrial sector for manufacturing control [2], equipment monitoring and control [3], and structural health monitoring [22]. Wireless sensor networks are composed of lowpower embedded sensor nodes that are connected through self-forming, self-healing wireless networks with flexible topologies. Nodes are distributed throughout the target environment, sometimes at random, sometimes attached to or embedded in objects. Traditionally, sensor networks have a small number of gateway nodes for streaming sensor data off the network or for interrogating the network state.

A ubiquitous compliance system based on the sensor network model can be build by scattering wireless nodes throughout the work site or by attaching nodes to workrelated objects and people. To measure vibration we need nodes with vibration sensors or accelerometers, attached to vibrating equipment and/or people. While placing sensor nodes on people would allow direct measurement of vibrations experienced by operatives, such a set-up might run into usability and acceptance problems. Attaching sensors only to machinery would still make it possible to estimate human vibration exposure, similar to the way exposure is currently estimated using knowledge about surface conditions and equipment characteristics.

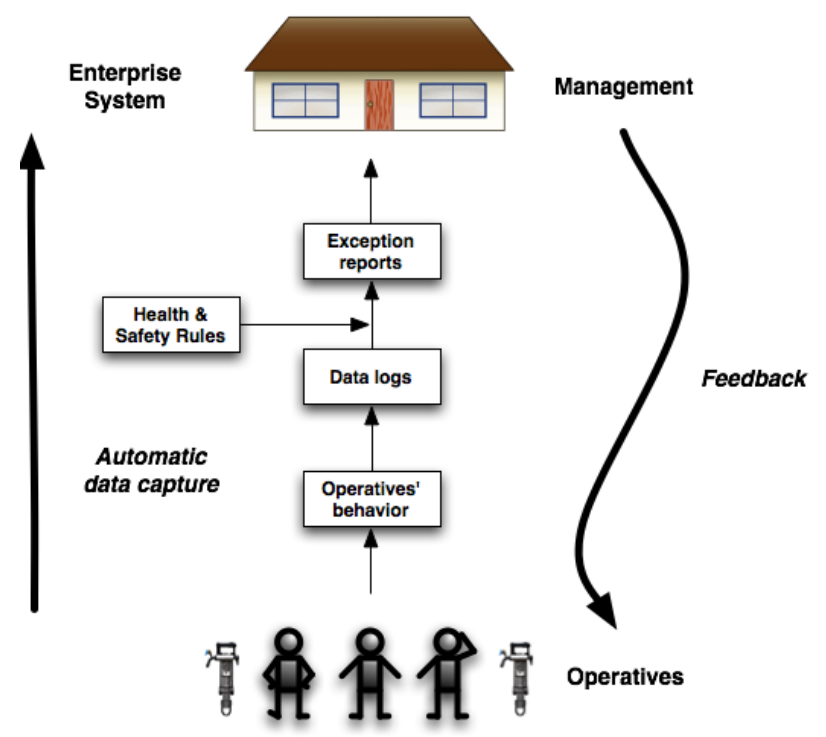

Fig. 1. Sensor-network inspired compliance system 
A gateway node would connect the sensor network to a back-end enterprise system, which can be located in the company's central IT facilities. This enterprise system would permanently store sensor data and provide means for analyzing and summarizing data.

A compliance system based on a sensor network model creates a top-down compliance regiment as visualized in Figure 1. Data about operatives' behavior is captured in the field using sensors. Sensor data is streamed into a wired compliance infrastructure where it is stored in the form of data logs in a database. Data logs are then analyzed and compared against digitized health and safety regulations. If compliance violations are detected they are reported in the form of exception reports, which are forwarded to management on a regular weekly or monthly basis. The information contained in the exception reports provides indications in which way operatives violate health and safety regulations. This information is fed back to operatives, for example in the form of tailored training measures or through enforcement measures such as penalties. In that way, a sensor-network inspired compliance system is similar in character to the paper-based system that is currently in place. It improves the quality of the data that is available to the management (completeness and accuracy), while at the same time reducing the need for operatives and supervisors to manually keep track of work activities. It could be said that a sensor-network based compliance system improves the overall efficiency of the compliance monitoring process, but does not fundamentally change its character. This is in contrast to the smart artifact approach, which we describe next.

\subsection{The Smart Artifact Approach}

One of the key themes of ubiquitous computing is the vision of smart everyday objects, sometimes also called smart artifacts [23,24,25] or physical-digital object systems [26]. Such smart artifacts are objects of our everyday lives, augmented with information technology and equipped with sensing, computation, and communication capabilities, that are able to perceive and interact with their environment and with other smart objects. Smart artifacts retain their original use and appearance while computing supports a new quality of interaction and behavior. The vision of smart artifacts entails the notion of autonomy and self-directed actions based on previously collected information and knowledge about users. For example, a smart tool might adapt to its user's usage pattern and stop operating in harmful situations. In contrast, some researchers stress a people-orientated approach by postulating that smart artifacts should make people 'smarter' and empower them to make decisions and take actions as mature and responsible people [27]. According to this interpretation, the overall design rationale should aim to keep the user engaged and in control whenever possible [28].

The technological foundation for smart artifacts and sensor networks is very similar. In fact, researchers often build smart artifacts by placing sensor network nodes inside everyday objects, or by attaching nodes to the object. The difference between the sensor network approach and the smart artifact approach cannot be found in the technology but in the relation between technology and human. A sensor networks is an instrument for collecting data from the real world; it is not designed to be interacted with and is thus virtually invisible to humans. Smart artifacts, on the 
other hand, retain their physical nature and are conceptualized by humans in terms of the familiar everyday object they are based on.

Using smart artifacts, a compliance system can be realized in a completely different fashion (Figure 2). In the centre of the artifact-based compliance system is the smart artifact with a capability to observe the operative's behavior, to create a personalized health and safety record and to provide context-sensitive notices to the operator. Notices may be shown on a small embedded display and relate to the operator's state with regard to health and safety regulations, for example, if the operator exceeds the allowed daily exposure limits. In order to work, the smart artifact must have embedded knowledge about relevant health and safety regulations and the capability to interpret behavior with respect to these regulations (a partial technical solution was described in [29]). An artifact-inspired compliance system creates a feedback loop that enables the operator to watch and - if necessary - to adjust his behavior. This empowers the operative and puts him in control of his own health. It can be speculated that having real-time information about their health and safety status and being able to observe the impact of their actions promotes responsible behavior in individuals and encourages compliance with health and safety regulations. On the other hand, an artifact-based compliance system does not provide direct means for management to test compliance and to prove it to auditors, because compliance data is created and managed locally.

The two models described above represent opposing poles of a continuous design spectrum. Of course they can be combined and systems can be built that exhibit features of both.
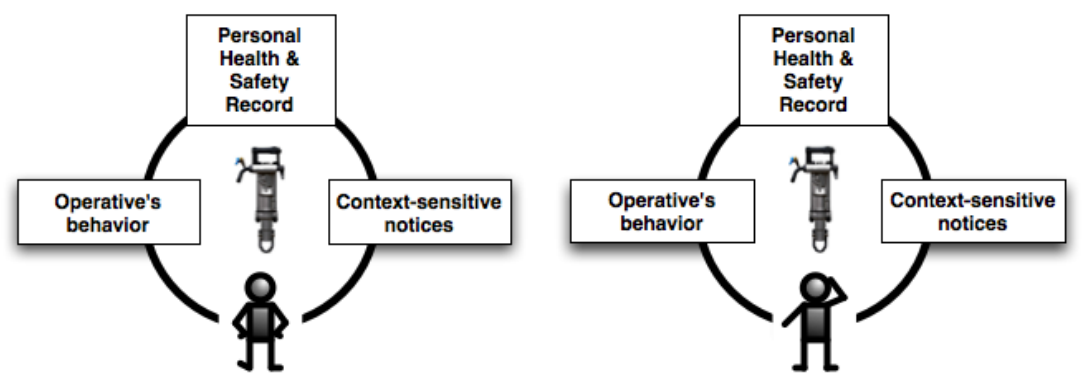

Fig. 2. Smart artifact inspired compliance system

\subsection{The Prototype System}

It is clear that neither the sensor-network approach nor the artifact approach alone is able to satisfy the needs of all stakeholders. The sensor-network approach captures data with the intention to satisfy audit requirements, but imposes a rigid top-down approach on the organization and overly emphasizes enforcement. The smart artifact approach supports a bottom-up approach to safety and emphasizes operators' responsibility, yet it does not address the management's need for centralized record keeping. 

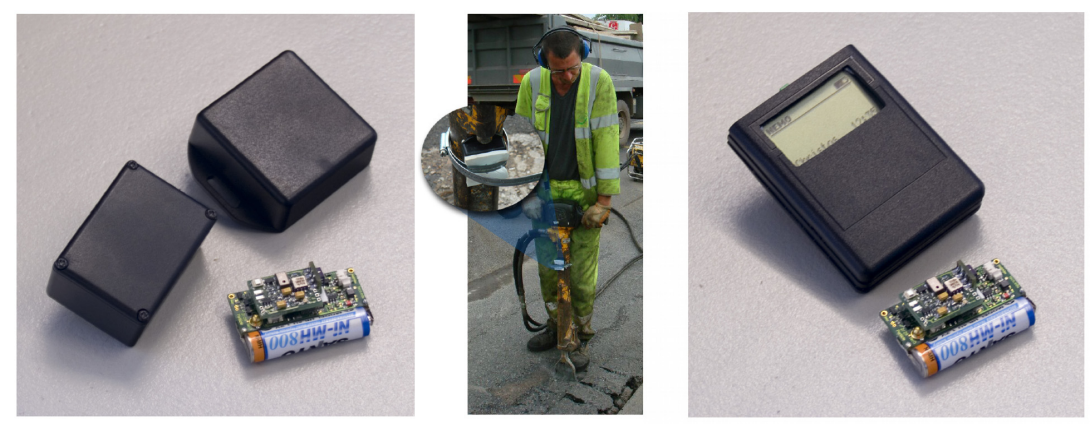

Fig. 3. Sensor-based vibration monitor system with wireless drill \& dosimeter (reproduced from [7]).

We have developed a sensor-based vibration monitoring system that falls somewhat between the sensor-network and the artifact model. It consists of a heavyduty pneumatic drill augmented with a wireless sensor node, and a wireless dosimeter that is worn by operators on top of their protective clothing (Figure 3). The drill measures vibrations using accelerometers, and the dosimeter records how often and how long an operative uses a drill. The dosimeter shows the user's current vibration exposure on a small display. Vibration exposure is estimated in cooperation between drill and dosimeter using information about the drill type and the duration of use. Dosimeters are personal devices: each operator uses his or her own device, yet the drill is shared among workers.

At the end of a workday, exposure data is uploaded to a backend database using a wireless communication gateway installed in vehicles. The database can be used by management to create compliance reports for each individual operative or for the whole workforce. We have tested the entire system in a 2-week long field trial at one of Safe-company's work sites and were able to estimate vibration exposure with an error of less than $8 \%$. Details about the implementation, experiences with the technical system and a report about the field trial can be found in [7].

\section{The Interplay between Technology and Organization}

A ubiquitous compliance system automates large parts of the compliance process. Actions and responsibilities that previously were in the hands of people are now taken on by technology. Such a system produces information about people, work activities and regulatory compliance at a level of detail that previously has not been available to the organization. It can be expected that the system and the information it produces will be appropriated by the various players to reshape how the organization works. Much of this reshaping will be unexpected and unintentional but we can assume that the effects will be profound.

A full assessment of these effects is not possible until after technology has been deployed on a large scale over a longer period of time. However, based on our observations and theoretical insights we are able to identify key organizational issues that will be affected by the introduction of ubiquitous compliance technology. These 
issues are captured by the 'compliance triangle' in Figure 4, which highlights three areas: (1) power and control, (2) rule formulation and (3) risk perception and risk behavior. In the following, we will explore these issues in more detail. Furthermore we will argue that the underlying system architecture of a compliance system will have a profound effect on how a system fits in the organizational context and how it will be appropriated.

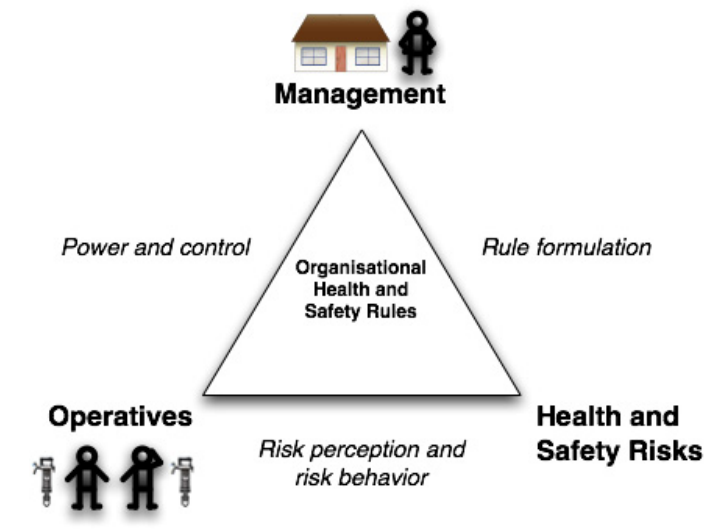

Fig. 4. Compliance triangle

In general, the relationship between rules and responsibility emerged as a key theme in our work. This relationship represents a double-edged sword for both management and operatives: For the latter, rule following without heedfulness may be irresponsible and potentially dangerous. At the same time, not complying with a rule - even when there appears to be a good reason for doing so - is potentially a disciplinary offence. For the former, rule writing which is abstracted from the realities of the rule application setting runs the risk of creating 'forced violations' - i.e. where operatives believe they have no choice but to break a rule in order to address specific local working conditions, or just to get the job done - and thus being wholly or partially ineffective in mitigating the underlying risks.

\subsection{Formulating and Representing Rules}

An organization must create an internal control system in order to comply with external health and safety regulations. The internal control system is a combination of explicit rules ("You must wear vibration gloves"), informal guidelines, work routines and business processes, with explicit rules representing only a small part of the overall control system. Yet a ubiquitous compliance system requires a digital representation of health and safety rules that is precise and unambiguous. In the case of vibration-related regulation the translation of external regulations into internal rules is straightforward because legislation is already formulated in very precise language, yet in other health and safety areas this is not necessarily the case. While this may limit the scope of a ubiquitous compliance system it also increases the burden for the organization to formulate effective and precise internal rules. On the other hand, it can 
be expected that technology progress will have an influence on how legal regulations are formulated in the first place.

A more immediate concern for operatives is the abstraction of rule writing from rule application. In our interviews we discovered strong reactions from operatives towards rules that had been formulated by management seemingly without comprehension of the consequences for operatives on the ground, including the predictable resentment at management enforcing rules that they themselves do not have to operate under (such as wearing full protective equipment on hot days whilst working with tarmac). There is also considerable frustration at 'blanket' rules that fail to recognize the variations in specific working conditions. We assume that the contrast between rule writing and rule application will be exacerbated by ubiquitous compliance technology as it increases the need for more precise and less flexible rules.

\subsection{Power and Control}

An issue that is often brought up in the context of ubiquitous computing and its impact on social interactions relates to privacy and surveillance. As Mark Weiser already pointed out, this issue is really about control [30]. In addition to health and safety purposes, information produced by a ubiquitous compliance system can be used by management to increase control over operatives, for example by creating more accurate logs of workers' activities. Even if the system is not used in that way by the management, operatives may perceive it in that sense. Similarly, a ubiquitous compliance system may be used in the future for purposes other than health and safety. From that point of view concerns about surveillance and control are understandable.

We found evidence for perception of control in how operatives view the GPS system deployed by Safe-company for tracking vehicles. The GPS system had originally been introduced to bring down insurance costs as vehicles had been stolen and is now occasionally used to locate people to send them to the nearest work site. At first, GPS units were installed inside vehicles, visible to drivers and operatives. Yet after some incidents where GPS units were damaged (possibly on purpose), units are now installed under the vehicles, with no indication when the unit is activated and able to track the vehicle. Operatives do not know much about this system apart from the fact that it is 'there'; they often do not even know whether this system works when the ignition is off. One operatives' perception of this technology is made clear by this statement: "It's a double edged sword, its good and its bad. We had a case last year, [...] one of our drivers knocked a lad down, and because the GPS was running, it recorded everything. And he was found ... he was under the speed limit so ... he was in the clear [...]. But we also had a case recently where two lads were pulled up for dangerous driving and speeding, yeah? [...] the dangerous driving bit was dropped, erm, but he went into an argument about the speeding, because the GPS recorded, [...] but it doesn't tell you where he was speeding (in relation to specific speed limits). So we had a situation where we were arguing here - backwards and forwards, backwards and forwards [...] but they (management) ended up saying [...] 'well, we know its speeding, but we can't say where', which to me, doesn't mean a thing." 
This example highlights both a perceived lack of trust and a lack of effective, twoway communication between management and operatives within Safe-company. Whilst there appears to be willingness on both sides, it is insufficient to ensure that management reasoning concerning the formulation and purpose of rules, and operatives' experience and expertise in the specifics of the setting, are effectively communicated to 'the other side'. The resultant lack of trust operates both in terms of management seeking to control the activities of operatives rather than trusting their common sense, and operatives ascribing less than altruistic motives to management in their imposition of rules, with self-preservation in a litigious environment or the desire to maximize profits seen as the 'real' motives behind them.

It is thus obvious that a ubiquitous health and safety system that follows the sensornetwork model with its implied top-down approach may exacerbate this situation and may lead to a pronounced conflict between management and operatives. If workers feel their privacy is violated, they can feel humiliated and depressed, and it is an open question how much an organization will benefit or lose from close surveillance of its employees. On the other hand, a ubiquitous health and safety system that follows the smart artifact approach and focuses on increasing operative's awareness does not directly intervene in the management-operative relationship. Indirectly such an approach may lead to a better understanding of health and safety issues on the operatives' part and facilitate communication. The generally positive attitude operatives shown towards the wearable dosimeters can be explained by the fact that in contrast to the GPS system the dosimeter design emphasizes awareness and personal control, rather than surveillance. In the word of one project manager: "I don't think people would object if you were clamping something onto them because they've got this view of safety [...] as long as you're clear that its not about measuring productivity. (So if for example the display that was on the machine - they could see what was being measured, they would feel comfortable with that, would they?) Yes, I think so. Yes, there's not a problem, it's a bit like all sorts of devices like that that often on sites and fork lift trucks and all that sort of stuff, but they wouldn't object. But the only thing they'd object is if its being used as I say linked to some sort of pay. Anything else they'd be fine."

Perception of technology is not only shaped by reality (what a technology is actually used for in an organization), but also by the narratives, stories and metaphors used to talk about it [31] In this context, it is interesting to note that operatives favorable compared the wearable dosimeters to mobile phones, again emphasizing the personal nature of the device and their control over it, rather than to GPS units (to which they bear a closer technical resemblance).

\subsection{Risk Perception and Risk Behavior}

As outlined at the beginning of the paper, there is a distinct lack of risk awareness among operatives, especially in connection with invisible risks. Mitigating invisible risks may require the suspension of ones own judgment in favor of compliance with prescribed organizational rules, such as wearing the required personal protective equipment. In this instance, a sense of self-efficacy - of feeling that one can work safely without following the rules or that the possible effects of this type of risk simply 'won't happen to me' - needs to be overridden by trust in the efficacy and 
applicability of organizationally devised rules and practices [32,33]. A ubiquitous health and safety system that exhibits features of the artifact-based approach may be able to support this process by raising the awareness of risks and aiding the understanding of organizational rules. This, however, is only possible when information is made available in situ, i.e. to operatives in the field while they are working.

Going one step further, a ubiquitous health and safety system could be designed to protect workers by automatically shutting down the drill whenever an operative reaches his or her exposure limit. While we did not test this feature in the field trial, we found support for both design options (warning-only and shutting down) among operatives and management. The argument for shutting down a tool is that it is the best way to enforce compliance with existing regulations. The arguments against is are that it will disturb work too much (for example if a job could be finished with another 30 seconds of drilling, but the tool will not allow it), that people will always find ways to work around technology (for example by swapping dosimeter tags) and that it takes control away from operatives instead of empowering them.

The latter point relates to the ongoing discussion about behavior-based safety $[34,35]$. The theory of behavior-based safety argues against the enforcement style approach to safety and emphasizes that employees need to take an ownership of their own safety as well as unsafe behaviors. Its purpose is to identify safe and at-risk behaviors, communicate the risk and help to identify safer solutions. The behaviorbased approach is fundamentally a data-driven decision-making process that relies on operatives as the basic source of expertise of behavioral change. Behavior-based approaches are controversial as they shift responsibility for health and safety to the workers without at the same time requiring significant change in the work processes. Nevertheless, an artifact centric compliance system could be able to empower operatives to observe and interpret their own behavior with respect to existing regulations, and to motivate them to modify their behavior if necessary.

While the extent to which an artifact-based system is able to support behaviorbased safety is mostly speculation at this point, we did observe initial signs of collaborative safety behavior. At more than one occasion, operatives would show their dosimeter tags to each other to discuss the meaning of the data and the level of their exposure. This can be interpreted as collaborative learning process that may lead to improved safety behavior.

\subsection{Dealing with Well-Intentioned Violations}

The underlying assumption of a ubiquitous compliance system is that any violation of health and safety rules is bad. While this is true in theory, we discovered that it is not true in practice. The term 'rule violation' may conjure up visions of deliberate sabotage, malicious damage or willful disobedience: in the vast majority of cases, however, the reality is far more mundane. A so-called 'violation' may be a habitual short-cut to a familiar procedure, a lax interpretation of a rule on the basis of perceived self-efficacy or experience, or a genuine attempt to get the job done in adverse circumstances (for example, in the absence of the proper equipment). Such violations are concerned with mismatches between rules and reality, and may be as simple as a worker not wearing anti-vibration gloves because he finds them 
uncomfortable. It is also clear from our data that routine rule violations are often condoned - implicitly or explicitly - by management, sometimes with a resultant perception by operatives of double standards and/or mercenary motives. In some cases, management 'turning a blind eye' may be viewed quite benignly, even when adverse consequences ensue. So, for example, one working foreman, who developed white finger syndrome through over-exposure to hand arm vibration whilst bringing a tree-clearing contract back on target, talked about the fact that management praised him for bringing the contract back on track even though they knew he was the only person with a chain saw ticket on the contract, and that he must have been going over the exposure limit. He did not blame them for this behavior, and, in fact, praised them for their responsiveness to the situation once he brought it to their attention. For others, their perception of such condoning is clearly part of a much more generalized, cynical perception of management as wanting to maximize profits or minimize the likelihood of being sued by workers in the event of accidents.

A ubiquitous compliance system that automatically records rule violations runs counter to such established practices, especially in the case of a sensor-network inspired system. If we accept that rule violations can be good - or at least that not all rule violations are bad - then a ubiquitous compliance system creates a potential problem for the organization in that it may make it impossible to circumvent the rules even if this is in the common interest of management and operatives An artifact-based system with its focus on local rather than global awareness does not pose the same problem, as it does not make information globally available.

\section{Conclusion}

Industrial health and safety is an important but as of yet largely unexplored application area for ubiquitous computing technologies. Our ubiquitous compliance system for controlling "vibration-white-finger" is one of the first examples of a ubiquitous health and safety system for industrial workplaces. The underlying architectural model of such a system has a strong influence on the linkage between technology and organization. A sensor-network model inspired system best supports a top-down compliance regiment that may exacerbate the already strained relationship between management and operatives because it promotes information imbalance, discourages workers' active participation in promoting and ensuring health and safety. A smart artifact inspired system, however, with a focus on raising operatives' awareness and control lends itself to a behavior-based safety approach in which health and safety policies emerge from the bottom up in the interplay between management and operatives. Other significant differences between these models can be identified in their influence on risk perception and risk behavior.

These models represent system archetypes that are helpful for exploring organizational issues. Any actual concrete system is most likely a mix of these models, inheriting advantages and disadvantages of both. While we can make some assertions about the possible impact of this technology on power relationships, perception and safety behavior it is too early to answer the crucial 'big' question, if the organization as a whole becomes more or less compliant as result of this technology, and if the technology actually contributes to a safer and healthier work 
environment. Answering these questions will require more technology development, field tests and observational studies.

\section{Acknowledgements}

This work has been supported by the UK Engineering and Physical Science Research Council (EPSRC) project NEMO (EP/C014677/1) and the EU project CoBIs (IST 004270). We would like to thank Daniel Boos (ETH Zurich) and Joe McCarthy (Nokia Research) for their helpful comments and suggestions.

\section{References}

1. Yearbook of Labour Statistics 2006, 65th issue. International Labour Organization, 2006.

2. Ota, N. and P. Wright. Trends in Wireless Sensor Networks for Manufacturing. International Journal of Manufacturing Research 2006 - Vol. 1, No.1 pp. 3 - 17, 2006.

3. Krishnamurthy, L., Adler, R., Buonadonna, P., Chhabra, J., Flanigan, M., Kushalnagar, N., Nachman, L., and Yarvis, M. Design and deployment of industrial sensor networks: experiences from a semiconductor plant and the north sea. Proceedings of the $3^{\text {rd }}$ Int. Conference on Embedded Networked Sensor Systems, Nov 2-4, 2005, San Diego, Ca.

4. Bardram, J.E. Applications of context-aware computing in hospital work: examples and design principles. Proceedings of the 2004 ACM Symposium on Applied Computing, 2004.

5. Stanford, V. Using Pervasive Computing to Deliver Elder Care. IEEE Pervasive Computing Vol.1, No.1 (January-March 2002), pp.10-13.

6. Lorincz, K., Malan, D.J., Fulford-Jones, T.R.F., Nawoj, A., Clavel, A., Shnayder, V., Mainland, G., Welsh, M., Moulton, S. Sensor networks for emergency response: challenges and opportunities. IEEE Pervasive Computing, Vol. 3, Issue 4, Oct.-Dec. 2004.

7. Efstratiou, C., Davies, N., Kortuem, G., Finney, J., Hooper, R., Lowton, M. Experiences of Designing and Deploying Intelligent Sensor Nodes to Monitor Hand-Arm Vibrations in the Field. In Proceedings of The 5th International Conference on Mobile Systems, Applications, and Services (MobiSys 2007), Puerto Rico, 11-14 June 2007.

8. Clegg, C.W., Coleman, P., Hornby, P., McClaren, R., Robson, J., Carey, N., et al. Tools to incorporate some psychological and organizational issues during the development of computer-based systems. Ergonomics, 39(3), 482-511, 1996.

9. Heller, T. If only we'd known sooner: developing knowledge of organizational changes earlier in the product development process. IEEE Trans. on Eng. Man., 47(3), 335-344, 2000.

10.Günter, H., Grote, G. \& Boos, D. Organizational issues in ubiquitous computing, Paper presented at 22nd EGOS Colloquium, Subtheme 14: Technology, Organization and Society: Recursive Perspectives. Bergen, July 06-08.

11.Doherty, N. F. \& King, M. An investigation of the factors affecting the successful treatment of organisational issues in systems development projects. European Journal of Information Systems, 10(3), 147-160, 2001.

12.Davies, C., Efstratiou, C., Finney, J., Hooper, R., Kortuem, G., Lowton, L. Sensing Danger - Challenges in Supporting Health and Safety Compliance in the Field. Proceedings of The $8^{\text {th }}$ IEEE Workshop on Mobile Computing Systems and Applications (HotMobile 2007), Tucson, Arizona, February 26-27, 2007. 
13.Iszatt White, M. Catching Them At It? An Ethnography of Rule Violation. Symposium on Current Developments in Ethnographic Research in the Social and Management Sciences. 13th-14th September 2006. Liverpool, UK.

14.Busby, J. and Iszatt White, M. Pushing the Boundaries of HRO Thinking: Non-complex and Uncoupled but still Deadly. SRA Annual Meeting - Risk Analysis in a Dynamic World: Making a Difference, 3rd-4th December 2006. Baltimore, Maryland

15.Ball, L.J., and Alford, D. What determines the acceptability of deontic health and safety rules? Proceedings of the $29^{\text {th }}$ Annual Conference of the Cognitive Science Society. Alpha, NJ: Sheridan Printing, August 1-4, 2007, Nashville, Tennessee.

16.Power, M. The Audit Society: rituals of verification. OUP, Oxford, 1997.

17.The Control of Vibration at Work Regulations 2005. Statutory Instrument 2005 No. 1093 The Stationery Office Limited, ISBN 0110727673.

18.Bovenzi, M., Griffin, M., Hagberg, M. (Eds.) Proceedings of the $2^{\text {nd }}$ International Workshop on Diagnosis of Injuries Caused by Hand-Transmitted Vibration. Goteborg, Sweden, 6-7 Sep 2006. Report no 14, Occupational and Environmental Medicine, ISSN 1650-4321.

19.Health and Safety Executive. Control the risks from hand-arm vibration. Advice for employers on the Control of Vibration at Work Regulations 2005.

20. King, N. Template Analysis. In G. Symon \& C. Cassell (eds.) Qualitative Methods and Analysis in Organizational Research: A Practical Guide. London, Sage, 1998.

21.Hilty, L.M., Som, C., Köhler, A. Assessing the Human, Social, and Environmental Risks of Pervasive Computing. Human and Ecological Risk Assessment, 10: 853-874, 2004.

22. Kim, S., Pakzad, S., Culler, D., Demmel, J., Fenves, G., Glaser, S., and Turon, M. Wireless sensor networks for structural health monitoring. In Proc. of the $4^{\text {th }}$ international Conference on Embedded Networked Sensor Systems, Oct 31-Nov 3, 2006, Boulder, Colorado.

23.Beigl, M., Gellersen, H.W., Schmidt, A. Mediacups: experience with design and use of computer-augmented everyday artifacts. Computer Networks, v.35 n.4, p401-409, 2001.

24.Siegemund, F. A Context-Aware Communication Platform for Smart Objects. Proceedings of the 2nd Int. Conference on Pervasive Computing, Linz, Austria, April 18-23, 2004.

25.Mattern, F. From Smart Devices to Smart Everyday Objects. Proceedings of Smart Objects Conference 2003 Grenoble, France, May 2003.

26.L. Nelson and E. F. Churchill. User Experience of Physical-Digital Object Systems: Implications for Representation and Infrastructure. Paper presented at Smart Object Systems Workshop, in cojunction with Ubicomp 2005, Tokyo, September 2005.

27.Streitz, N.A, Rocker, C., Prante, T., van Alphen, D., Stenzel, R., Magerkurth, C. Designing Smart Artifacts for Smart Environments. IEEE Computer, vol. 38, no. 3, March, 2005.

28.Rogers, I. Moving on from Weiser's Vision of Calm Computing: Engaging UbiComp Experiences. Proceedings of the $8^{\text {th }}$ International Conference of Ubiquitous Computing. California, USA. 17-21 September 2006.

29.Strohbach, M., Gellersen, H., Kortuem, G., Kray, C. Cooperative Artefacts: Assessing Real World Situations with Embedded Technology. Proceedings of the $6^{\text {th }}$ International Conference on Ubiquitous Computing, Springer, Berlin, Heidelberg, New York, 2004.

30.Weiser, M. The computer for the 21st century. Sci Am 265:94-104.

31.Kendall, J.E. and Kendall, K.E. Metaphors and their Meaning for Information Systems Development. European Journal of Information Systems, Vol. 3, No. 1, 1994, pp. 37-47.

32.Rebecca, L. Not Working to Rule: Understanding Procedural Violations at Work. Safety Science, 28, 2, 77-95.

33.Hale, A.R., Heijer, T. and Koornneef, F. Management of Safety Rules: The Case of Railways. Safety Science Monitor, 7, 1, 2003, 1-11.

34.E. Scott Geller, Behavior-Based Safety and Occupational Risk Management. Behavior Modification, Vol. 29, No. 3, 2005, 539-561.

35.Hopkins, Andrew. Lessons from Longford: the Esso Gas Plant Explosion. CCH, Canberra, Australia, 2000. 